\title{
CORPORATE GOVERNANCE AND PERFORMANCE MANAGEMENT SYSTEMS AT DHI COMPANIES: EXPERIENCES OF MANAGING CHANGE
}

\author{
Kharka Damber S., Denka, Tshering and Nima, Dorji \\ Director,Druk Holding and Investments, Bhutan \\ damberkharka@dhi.bt \\ Analyst, Druk Holding and Investments, Bhutan \\ tsheringdenka@dhi.bt
}

Senior Analyst, Druk Holding and Investments, Bhutan

dorjinima@dhi.bt

\begin{abstract}
The Druk Holding and Investments (DHI), a government holding company in Bhutan that owns and manages majority of the state owned enterprises and holds government shares in many of the publically listed companies, has been initiating corporate governance andperformance management reforms over the last eight years since its establishment in November 2007. Introduction of corporate governance practices in line with international good practices and introduction of performance management system in the state owned companies called for managing change. This paper, after a general introduction of the concept of change management, shares the experiences in change management. The paper highlights some of the initiatives undertaken by $\mathrm{DHI}$ and its companies, and underscores that success of introducing a new system is more certainwhen changes are introduced through a consultative process.
\end{abstract}

Keywords: Ownership Policy, Corporate Governance, Annual Compacts, Performance Management System, Chairmen's Forum, CEO Round Table Meeting, CXO Forum

\section{Council for Innovative Research}

Peer Review Research Publishing System

\section{Journal: International Journal Of Management \& Information Technology}

\author{
Vol. 11, No 2 \\ editorsijmit@gmail.com
}

www.ijmit.com 


\section{INTRODUCTION}

Change is a concept rather than a solution. But it is not a concept that can be packaged like a commodity and made available in the market for sale. The process of change takes an organization from an 'as-is state' to a 'desired state' through a set of intermediate interventions. Some questions pondered upon while introducing a new product in a market are: "What does a customer need?" "What is his ability to pay?" and "Who are the competitors?" Organisational vision, its current state of business and the desired state of business, which takes the organization towards its vision, are important factors in determining what changes are required in the organisation. However, the difference between introducing a product and introducing a change lie in the fact that the manufacturer who supplies a commodity can provide a certain guarantee on the performance of the newly introduced product.Whereas, a consultant who recommends a particular change in an organization and those who initiate the change are not in a position to guarantee success of change implementation.

Introducing change in any organization is difficult, costly, time consuming, risky and normally lacks support of many employees, mainly due to challenges in adapting to new systems and the usual fear of facing discomfort and even losing jobs. However, change is important and almost inevitable in order to reshape and reposition organizations to be in line with the company's vision and to meetthe emerging challenges.

Nickols (2008) states, managing change is a challenge as it is not without resistance from different corners. Resistance begins even before the necessary change is identified. Firstly, even to commence a study to see if changes are required never sells smoothly to employees. Secondly, reluctance prevails when the change process starts even at the level of involvement and participation for identification of areas and processes of change. Third, when finally the changes are identified the phase of implementation starts, the process will face poor acceptance as it calls for extra effort, extra knowledge and skills, extra costs and risks as there is no guarantee for success in achieving the intended result.

Any introduction of change in the companies that are already functioning with certain norms and values that may have become embedded in their institutionbecomes difficult for reasons outlined. However, for commercially oriented State Owned Enterprises (SOEs), it is very important to follow internationally accepted norms of corporate governance practices for achieving corporate performance. Druk Holding and Investments (DHI), as it was set up for managing SOEs, needed to bring about governance changes to improve corporate performances that included improvement in learning and growth of the companies, internal business systems and processes, higher levels of customer satisfaction and ultimately the improvement in financial performances.

\section{ABOUT DHI}

DHI was established through a Royal Charter issued by His Majesty on November 11, 2007. The primary purposes of DHI are to hold and manage commercial companies of the Government, to make new investments, to raise funds and to promote private sector development in Bhutan.

The following chart provides information on different SOEs with DHI's percentages of share holdings grouped under relevant economic sectors.

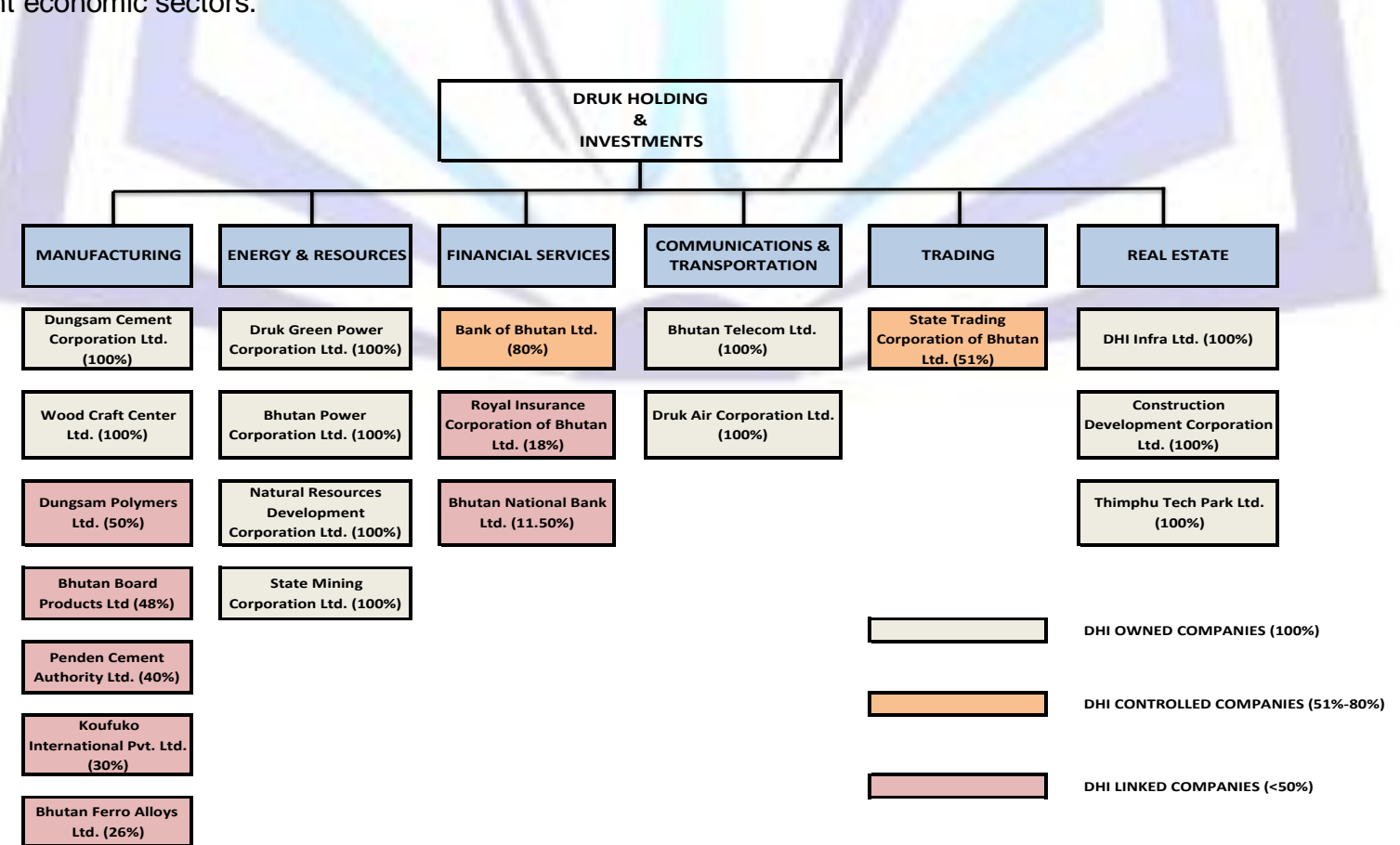

Figure 1: SOEs under DHI 
Currently, DHI fully owns eleven companies and holds shares ranging from $14-80 \%$ in nine other companies. These companies operate in the energy, telecommunication, aviation, natural resources, and financial and manufacturing sectors.

\section{CHANGES INTRODUCED}

In the last eight years, a series of changes in areas of corporate governance in line with the OECD Corporate Governance Principles were introduced for improving corporate performance at Druk Holding and Investments (DHI) and its portfolio companies ${ }^{1}$. Corporate performance systems and procedures were developed and put in place. At the time of the formation of the holding company, some companies already practiced some of the modern systems and procedures that ensured proper planning, monitoring and evaluation of corporate performance while others had not introduced such practices.

Once the SOEs were brought under the holding structure in November 2007, a series of new management systems for some companies and modification of existing systems in some others were introduced. New systems for which ideas were initially conceptualized at the company level or changes that were finalized after detail discussion with the companies were found to have very little resistance, if any. Companies that had modern management practices in place became sources of encouragement for others for acceptance of changes in their existing systems.

Some of the changes that $\mathrm{DHI}$ introduced in areas of corporate governance and performance management systems since its establishment are:

\subsection{Corporate Governance}

DHI developed an Ownership Policy (OP) and Corporate Governance Code (CG code) and released them for implementation by all DHI companies. These documentsprovide principles and procedures for Corporate Governance.

Among others they provide guidelineson:

- Interface between the companies, shareholders and the government

- Board composition, appointment, responsibilities, authority, fiduciary duties and liabilities and board evaluation

- CEO selection and appointment, roles and responsibilities and performance evaluation

Although the Companies Act of Bhutan 2000 provides corporate governance guidelines, the Ownership Policy (OP)and CG Code developed by DHI are Company Act Plus in many areas. The OP development process was highly consultative and has undergone several discussions among the DHI Board Members led by the Chairperson, the Board Directors and CEOs of the companies. The DHI Board approved the document after about a year of discussions. In the initial phase of the discussions there were areas on which companies and their directors had reservations. However, things became clearer after several rounds of discussions as most comments and suggestions got clarified or incorporated. By the time the final draft was tabled for discussions in the form of a workshop, the acceptance level was unanimous among CEOs and directors of $\mathrm{DHI}$ companies. The leadership role of the DHI Chairman was crucial in driving the process to consensus. The fact that the document was modelled based on the international best practice benchmarksof the "OECD Guidelines on Corporate Governance of State Owned Enterprises" to an extent helped the companies gain confidence in the draft. Ultimately, it was the process of engaging the relevant stakeholders while developing the policy that mattered in the unanimous acceptance of this important policy document. The ownership policy and CG code documents were revised at a later stage using the services of an international expert and the revised version approved in 2013is currently being practiced.

In order to provide proper structure and increased capability for the implementation of standard corporate governance system aimed at enhancing corporate performance, the following initiatives were undertaken.

- Introduction of Chairmen's Forum: Initiated as a high-level discussion platform whereby Chairpersons of the DHI companies are provided a separate space, beyond the call of Board Meetings, where strategic conversations related to board processes and other corporate governance areas take place. The forum is held at least twice a year and the corporate performance department of $\mathrm{DHI}$ takes advantage of this space to make presentations and updating the chairpersons on important aspects of corporate governance.

- Introduction of CEO Roundtable Meeting: CEOs of DHI companies meet at least four times a year to discuss cross cutting issues and share company wise business experiences. Besides this, the forum provides feedback on any corporate governance related issues.

- Introduction of CXO Forums: CXO are the second level officials in the companies representing different departments/divisions. They meet three to four times a year and discuss issues related to their own functional areas. This forum has enabled better understanding among the professional groups and helped build relationships. Crosscutting issues affecting companies discussed at this level are often submitted to the CEO Roundtable Meeting for further directives.

\footnotetext{
${ }^{1}$ Corporate governance principles suggested by the Organization for Economic Co-operation and Development (OECD) focuses on transparency and disclosure, rule of law, right of shareholders, equity and fairness etc.
} 
- Institutionalisation of Board Directors Orientation Program on Corporate Governance and Performance Management: $\mathrm{DHI}$ conducts a two-day program every year to orient newly appointed directors on corporate governance and performance management systems.

- Professional Directors Training Program: In order to grow the pool of professionally trained board directors who sit on all DHI company boards, DHI coordinates and conducts a professional directors training program in partnership with reputed institutions around the world that have the capacity and knowledge, particularly in the area of the boards role in strengthening corporate governance and monitoring performance. Countries around the world (Sweden, Philippines, Malaysia, Singapore, etc.) and even within our region have begun to make directorship training a requirement to qualify as a board director.

- Leadership Development Program for senior managers: This program is institutionalised by DHI and organisedmore frequently as it is part of the holding company's way of supporting succession planning for leadership positions. The training targets senior leaders who are in a position to fill the leadership vacuum within the DHI companies.

- Introduction of Company Secretary's Manuals: This is one of the more important among several manuals and handbooks developed by $\mathrm{DHI}$ to be used by companies in streamlining their processes and in particular, specifying the roles and responsibilities of critical personnel, such as the Company Secretary, in ensuring proper implementation and compliance of corporate governance best practice. A Company Secretary's training is organized to complement the manual and to orient newer company secretaries in their roles and responsibilities.

One of the major intent of institutionalising different forums is to create ownership of the companies in areas of common processes, policies and guidelines that are developed and circulated for implementation in all companies. Initially the experience was not very good when new processes and guidelines were introduced. However, resistance to change has really eased up as CEOs, Chairpersons and senior managers have become more involved through different forums for discussion of different issues. These platforms have really helped in shifting the onus to the leadership in ensuring the success of implementing the necessary changes. Given the past experience, DHI also realised that introducing too many reforms within a short span of time proves to be counterproductive and hence adopted amore gradual introduction of changes.

$\mathrm{DHI}$ initiated several guidelines involving different forums and are commonly used in all the DHI owned companies. These are:

(i) Corporate Performance: Target formulation and evaluation guideline

(ii) Investment guideline

(iii) Dividend guideline

(iv) Risk Management guideline

(v) Board recruitment guideline

(vi) Board evaluation guideline

(vii) CEO recruitment guideline

(viii) CEO performance evaluation guideline

(ix) Common HR guideline

(x) Corporate Social Responsibility guideline

All these guidelines are developed using lessons from global best practicesparticularly as provided in the OECD and International Financial Corporation (IFC) resources. It is obvious that putting good corporate governance in place promotes transparency, fairness, and equity and ultimately helps strengthen the organization's overall governance. However, performance management tools should also be put in place so that one can keep track of improvement, if any. As it is popularly said that something that is not measured is difficult to be managed, DHI introduced measurement systems for performance management of companies as explained in the rest of the sections. Rest of the sections explain the performance management system at the DHI companies.

\subsection{Performance Management Systems}

\section{a. Annual Compact}

$\mathrm{DH}$ introduced a system of signing annual compacts with its Board and the companies ${ }^{2}$. The system first introduced in 2008 sets annual performance targets, reviews and evaluates performance, and links performance indicators to corporate incentives in DHI owned companies and the Bank of Bhutan, a DHI controlled company. The compact contains activities with clearly measurable targets to be accomplished during the year. It is a corporate level performance management system that covers target setting and monitoring \& evaluating in performance areas of (i) financials, (ii) customer service, (iii) corporate governance and, (iv) policy directed targets. In early 2012, after an initial implementation period of over three years, DHI reviewed the existing compact system and adopted a few changes to streamline the compact process and rationalize Key Performance Indicators (KPIs) to further enhance the performance of the companies. With regard to customer satisfaction, in addition to hard data obtained from the companies, an independent annual customer survey is also conducted for each service-oriented company to arrive at the customer perception index. Depending on the nature of each company, the weightages on each performance area are assigned at the time of compact finalization following the principles of the established compact management system.

\footnotetext{
2 Annual compact that is in line with the principles of performance dashboard proposed by Norton and Kaplan (1996) was developed and put in practice.
} 
Implementing the Compacts

The performance management system has been well received and is very successfully implemented over the last few years. The success could be attributed largely to the fact that the compact targets are negotiated based on the past trends of each company's performance and based on the expectation of changes in the economic variables.

The Annual Compact is a mutual agreement rather than a one-sided demand placed by the shareholder. There is a series of discussion that takes place initially at the company management level followed by discussions at the company board level. After the targets are discussed at the company board level, it is again discussed with the DHI secretariat before finally being placed for negotiation between the $\mathrm{DHI}$ board and the Company board. It is only after the finalisation by the two boards that the compact is signed. DHI has a developed process and approved time line to manage the compact process that all $\mathrm{DHI}$ companies are prescribed to.

Table 1. Annual Compact Management Timeline

\begin{tabular}{|l|l|}
\hline \multirow{2}{*}{ November } & $\begin{array}{l}\text { DHI and Ministry of Finance (MoF) engage in DHI/MoF compact negotiation and MoF } \\
\text { provides specific Royal Government of Bhutan targets from relevant line ministries }\end{array}$ \\
\cline { 2 - 3 } & $\begin{array}{l}\text { Discussion/Negotiation of non-financial targets for following year between DHI and company } \\
\text { boards/management }\end{array}$ \\
\hline \multirow{2}{*}{$\begin{array}{l}\text { November/Dec } \\
\text { January }\end{array}$} & Discussion and finalization of compact for the following year for non-financial targets \\
\cline { 2 - 3 } & Assessment/evaluation of performance of previous year \\
\hline \multirow{2}{*}{ March } & $\begin{array}{l}\text { Discussion and finalization of financial targets between DHI and Company } \\
\text { Boards/management }\end{array}$ \\
\cline { 2 - 3 } & $\begin{array}{l}\text { Performance evaluation of the previous year and approval of performance based pay and } \\
\text { incentives. }\end{array}$ \\
\hline \multirow{2}{*}{ April } & Review of first quarter performance by the DHI Corporate Performance Department \\
\hline \multirow{2}{*}{ August } & $\begin{array}{l}\text { Submission and presentation of half yearly performance report by companies at Mid-term } \\
\text { Review Meeting }\end{array}$ \\
\cline { 2 - 3 } & $\begin{array}{l}\text { Joint review of half yearly performance by the DHI Board and Company Boards } \\
\text { Review of third quarter performance by the DHI Corporate Performance Department }\end{array}$ \\
\hline
\end{tabular}

\section{ii Target Setting Philosophy and performance evaluation Process}

- The Compact targets are closely aligned with the company's Strategic Plans and in the case of DHI owned companies, with their Five Year Investment Plans.

- Generally target setting on variables should be on the basis of previous period actual plus reasonable growth rate.

- If the previous year happens to be outlier (not normal year) then an average of immediate past three years or periods are considered giving due consideration to likely market changes.

- Targets for variables that are non-quantifiable in terms of measurable units then targets are set in terms of percentage of completion by certain timeline.

- For each target, detail on what it means, how it will be measured, and assumptions that may deter are clearly spelled out in the compact so as to avoid ambiguity at the time of evaluation.

- Board audit committee or performance evaluation committee of each company will evaluate the compact at the end of the year and present the report to the Board for finalization.

- DHI's corporate performance department reviews and validates data from original source

- Based on the target achievement, weightages assigned and the agreed process of evaluation for each target under each performance area,the evaluation committee does evaluation at the year-end. The total achievable point from four areas of performance measurement is set at $100 \%$.

- Based on the compact achievement the performance based variable allowance (PBVA) is approved for a company, which gets distributed to each employee in accordance to their basic pay as per the following table: 
Table 2. Performance Based Variable Payout Guideline

\begin{tabular}{|l|l|l|}
\hline \multirow{2}{*}{$\begin{array}{l}\text { Compact } \\
\text { Achievement }\end{array}$} & \multicolumn{2}{|c|}{ PBVA payout } \\
\cline { 2 - 3 } & CEO & Employees \\
\hline$\geq 95$ & $25 \%$ of annual basic pay & $15 \%$ of annual basic pay \\
\hline $75 \%-95 \%$ & $\begin{array}{l}\text { Prorated PBVA payout of } 1.5 \% \text { for } \\
\text { every point of achievement }\end{array}$ & $\begin{array}{l}\text { Prorated PBVA payout of } 0.75 \% \\
\text { for every point of achievement }\end{array}$ \\
\hline$\leq 75 \%$ & No PBVA payout & No PBVA payout \\
\hline
\end{tabular}

In order to create more stringent performance monitoring and evaluation processes for the CEO, the CEOs of the DHI companies receive their PBVA based on a total CEO's performance rating point which constitutes $20 \%$ from a leadership performance rating carried out by the Board and $80 \%$ from the company's compact achievement.

\section{b. Employee Level Performance Assessment}

In addition to corporate level compact management, performance management systems (PMS) and performance based Incentive systems (PBIS) are practiced in all the companies in order to encourage division and individual level performance enhancement. This system allows division and individual level target setting (in line with the corporate level compact) and performance monitoring. The Annual Compact defines the overall corporate level targets, which are then cascaded down to different levels within the company (department, division, units) and ultimately define individual employee level performance targets. The individual performance metric is the performance target agreed between the supervisor and the subordinate. Individual performance ratings and individual target achievement is tied to the annual bonus and has other HR linkages to meritorious, fast track and general promotions within the company. The PMS has been implemented successfully at DHI,its owned companies and linked companies. The introduction of and implementation of PMS has had almost no resistance, as there were many success stories to be shared by those companies that were already practicing this system.

\section{CONCLUSION}

To conclude, managing change with respect to introducing several corporate governance practices and performance management systems at the DHI companies were not without resistance at least during the initial stage. Even to commence a study to identify the changes thatwere required was not accepted smoothly by employees of the companies and even the company board members. Reluctance prevailed when the process started even at the level of involvement and participation for identification of systems and processes for change. All were initially concerned about extra effort, need for extra knowledge and skills, extra costs and risks including personal risks such as probability of being retrenched. There was also no guarantee of success in terms of achieving the intended results by introducing changes. However, many of the changes, particularly with regards to new systems that were introduced,werefinally accepted quite successfully and the results have started showing in terms of better business processes leading to higher customer satisfaction and finally producing improved financial achievement in most companies.

To reflect on the processes of change management (introducing corporate governance best practices and performance management systems) that led to success, the following lessons are shared:

- Learning from the well functioning companies themselves on the best practices and sharing experiences with other companies in the informal forums such as CEO round tables meeting held every quarter has played an important role in introducing changes successfully.

- $\quad$ CEOs and the senior management team playing roles as champions of change management have been crucial in the successful identification of areas of change.

- Involvement of key members during the process of change identification and implementation proved useful.

- Realization of parent company to deal with change management as facilitator and allowing change areas conceptualized among leaders of companies through cross fertilization of ideas in informal discussion forums resulted in ownership of the idea.

- Leadership role in discussion forums in explaining desired change, involving people in the process and the art of arriving at consensus played a role in generating a "feel good factor" and confidence about the outcome of the proposed change.

- $\quad$ CEOs and CXOs (Department heads) in companies directly influence the uptake of new system by their people as they direct them on a day-to-day work, so any change that is not perceived important by these people is bound to bounce back as it is forcefully introduced.

Today, companies have adopted all the changes introduced since the creation of the holding company rather successfully. The principles of corporate governance highlighted within the Corporate Governance Code, functional relationship and interface management through the Ownership policy, etc. are successfully and effectively adopted by all DHI owned and controlled companies. Additionally, other companies also continue to replicate and institute the Performance Management System looking at the proven direct linkage of performance monitoring and assessment of the companies that have instituted PMS and how it inevitably links to their financial achievement. 


\section{REFERENCES}

1. Arguden Y (2010), "A Corporate Governance Model: building responsible Boards and Sustainable Businesses", A Global Corporate Governance Forum Publication, Issue 17.

2. Fred Nickols (2008), "Change Management 101: A primer”, Distance Consulting LLC, www.nickols.us/change.htm

3. International Finance Corporation (2005),"OECD Guidelines on Corporate Governance of State - Owned Enterprise".

4. International Finance Corporation (2008), "Introduction to Corporate Governance", Corporate Governance Board Leadership Training Resources KIT.

5. Kaplan, R. S., \& Norton, D. P. (1996), "The balanced scorecard",Boston HBS Press.

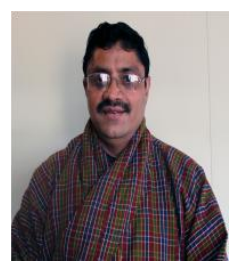

\section{Dr. Damber S Kharka}

Dr. Damber S. Kharka is a Director at Druk Holding and Investments, Bhutan, a sovereign government holding company that manages state owned enterprises and acts as the investment arm of the state. He has substantial experience in training, consulting and research in different disciplines of management as a result of his nineteen years academic career at the Royal Institute of Management. Besides having provided consulting and training services for several years, he also has to his credit many papers published in national, regional and international publications. He had very successfully transited from the world of academia to the corporate sector and it is his eighth year as an executive in the corporate sector in Bhutan. Dr. Kharka has been the key initiator for development and implementation of corporate governance and performance management systems in the $\mathrm{DHI}$ subsidiaries and possesses rich experience as a board director in a number of companies and as a trainer for directors in areas of corporate governance, finance and performance management.

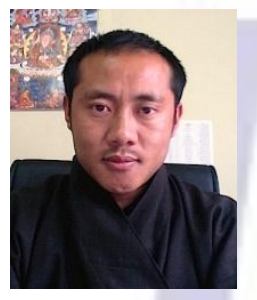

\section{Dorji Nima}

Mr. Dorji Nima is a Senior Analyst at Druk Holding \& Investments Ltd. responsible for planning monitoring and evaluation of performances for the SOEs in Bhutan. Before that, he worked as an Analyst for DHI's Consulting Services Unit for more than two years. He worked for few years at Bhutan Post Corporation before joining the $\mathrm{DHI}$ and gained corporate experiences that helped him contribute in developing and implementing corporate governance and performance management systems at the DHI. He has a Masters degree in Business Administration (MBA) from Australian Graduate School of Entrepreneurship, Melbourne, Australia.

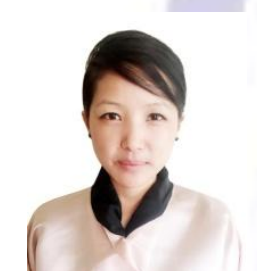

\section{Tshering Denka}

Tshering Denka has an undergraduate degree in economics from Wheaton College in the United States, and a postgraduate degree in public policy from KDI School of Management in Seoul, Korea. She began her career in the nonprofit sector working for a nonprofit organization in Washington DC and later worked at the Bhutan Foundation in Thimphu. She transitioned into the corporate sector in Bhutan after completion of her postgraduate degree in Korea when she joined Druk Holding and Investments (DHI) as an Analyst with the Corporate Performance Department. Her experience at DHI has been focused mostly on strengthening Corporate Governance and institutionalizing CG best practice and norms within the $\mathrm{DHI}$ and $\mathrm{DHI}$ owned state-owned enterprises in Bhutan. 